\title{
A violência no campo e a cobertura nos jornais impressos diário do Pará e o Liberal: uma análise dos casos Dorothy Stang e José Cláudio Ribeiro
}

\section{The violence in the field and the coverage in the newspapers diário do pará and o liberal: an analysis of the cases Dorothy Stang and José Cláudio Ribeiro}

Ana Lídia Azevedo de Campos - Graduada em Turismo pela Universidade Federal do Pará (2007) e em Comunicação Social - Jornalismo pela Universidade da Amazônia (2014). E-mail: alidia.campos@gmail.com.

Nírvia Ravena - Possui graduação em Ciências Sociais pela Universidade Federal do Pará (1988), mestrado em Planejamento do Desenvolvimento pela Universidade Federal do Pará (1994) e doutorado em Ciência Política (Ciência Política e Sociologia) pelo Instituto Universitário de Pesquisas do Rio de Janeiro/IUPERJ (2004). E-mail: niravena@gmail.com.

\section{Resumo}

Este trabalho apresenta uma análise da cobertura da violência no campo feita pelos jornais impressos Diário do Pará e O Liberal, tendo como objeto de estudo o assassinato de Dorothy Stang, em 2005, e do casal José Cláudio Ribeiro e Maria do Espírito Santo, em 2011. Depois de um apanhado histórico da violência no campo no Pará, incluindo a atuação da Comissão Pastoral da Terra (CPT) e a descrição dos assassinatos, apresentase um conjunto teórico de suporte para a análise além de uma descrição sucinta dos jornais pesquisados. $O$ trabalho traz a análise quantitativa e qualitativa de matérias referentes ao tema violência no campo, bem como ao assassinato da missionária e à morte do casal de ambientalistas, seguindo uma mesma linha de pesquisa em ambos os casos. Por fim, são apresentadas as considerações do tema abordado levando em conta o encontro de teoria e prática.

\section{Palavras-chave}

Violência no campo. Agendamento. Opinião pública. Valor notícia,Jornal impresso. Dorothy Stang. José Cláudio Ribeiro.

\begin{abstract}
This paper presents an analysis of the coverage of violence in the field by the newspapers Diário do Pará and O Liberal. The object of study is the murder of Sister Dorothy Stang, in February 2005, and the couple of environmentalists José Cláudio Ribeiro and Maria do Espírito Santo, in May 2011. After a brief history of the violence in the field in Pará State, including the activities of the Comissão Pastoral da Terra (CPT) and the description of the murders, it presents a review of theoretical concepts, plus a brief description of Diário do Pará and O Liberal. Then, it contains the quantitative and qualitative analysis of these newspapers in the coverage of violence in the field and the murder of the missionary and the couple, following the same line of research. Then, the considerations of the subject are presented taking into account the intersection between theory and practice.
\end{abstract}

\section{Keywords}

Violence in the field. Scheduling. Public opinion. Newspaper. Dorothy Stang. José Cláudio Ribeiro. 


\section{INTRODUÇÃO}

O Pará passou por uma discussão em torno da divisão do mesmo em três Estados (Tapajós, Carajás e Pará remanescente). A decisão foi tomada por meio de um plebiscito entre os habitantes paraenses, no segundo semestre de 2011. Sendo negativa a maioria dos votos para a criação do Estado de Carajás (66,60\% a 33,4\%) e para a criação do Estado do Tapajós (66,08\% a 33,92\%), o Pará continua sendo o segundo maior Estado brasileiro, com 1.248.042,515 Km², divididos em 144 municípios - perde apenas para o Amazonas, com 1.577.820,2 $\mathrm{Km}^{2}$ de área absoluta.

Com aproximadamente 7.321.500 habitantes, a maioria concentrada em zonas urbanas, há uma extensa área rural no Pará pouco povoada, explorada principalmente por latifundiários, madeireiros e grileiros e onde ocorrem conflitos entre estes e os que buscam pôr em prática a reforma agrária, a preservação ambiental, o trabalho na agricultura, entre outros. Estes atores da agricultura familiar são caracterizados pela diversidade sócio-econômica na relação com a terra e suas práticas diferem pela diversidade através da qual a agricultura é realizada (Hurtienne, 2008) São milhares de fatos envolvendo ribeirinhos, comunidades, empresários, sem-terra, trabalhadores rurais, ambientalistas e grileiros, mas os desfechos não são muito diferentes: assassinatos, massacres, ameaça às famílias dos envolvidos e impunidade.

Violência, por sua vez, está entre os temas de notícias veiculadas na mídia impressa. Devido à sua importância e, principalmente, ao interesse dos leitores, criou-se um caderno que trata especificamente de assuntos relacionados a crimes (caderno Polícia). Os jornais impressos estampam fotos e informam sobre o fato, em matérias sucessivas, entrevistando pessoas envolvidas no caso, testemunhas, policiais, autoridades responsáveis pela administração dos municípios, do Estado, entre outras.

É importante, portanto, observar como é feito o agendamento, a escolha do que deve ser veiculado e que destaque os fatos terão nos jornais paraenses; se as direções de redação disponibilizam viagens para repórteres apurarem nos locais dos crimes, bem como se os fatos ocorridos no Pará têm mais importância para os jornais do Estado, ou seja, se ganham maior destaque do que os que ocorrem fora.

Unindo a relevância que assuntos ligados à violência no campo têm para a população à curiosidade quanto ao nível de cobertura de jornais sobre este tema, surgiram as perguntas: "Como os jornais impressos paraenses cobrem os casos relacionados à violência no campo e qual a importância dada pelos jornais para estes assuntos?". 
Para respondê-las, foram escolhidos dois casos que tiveram grande repercussão: o assassinato da missionária Dorothy Stang, em Anapu, e do casal de ambientalistas José Cláudio Ribeiro e Maria do Espírito Santo, no município de Nova Ipixuna. O meio de difusão das notícias selecionado para esta pesquisa foi o jornal impresso, sendo que os dois jornais paraenses de grande circulação são O Liberal e o Diário do Pará, produzidos em Belém.

Porém, é impossível tratar destes assuntos sem fazer um apanhado histórico da ocupação das terras paraenses, principalmente a partir de 1960, quando se intensificaram as migrações de povos de diversas cidades brasileiras para o sul do Pará, onde houve concessões de terras e não foram obedecidas as regras de limites para a apropriação das áreas.

Considera-se que o tema 'violência no campo' exige uma abordagem além da factual, por ser um assunto ligado à política, à economia, à cultura e à ideologia, e por este motivo não se costuma publicar os fatos no caderno policial. Mesmo assim, é necessário aliar a prática à teoria. Neste sentido, o estudo teórico do tema é baseado na teoria do jornalismo, incluindo opinião pública, valor notícia, agendamento (agenda-setting), além de fundamentos do jornalismo impresso. Há também um breve histórico dos jornais O Liberal e Diário do Pará.

Para dar andamento ao estudo, foi realizada uma análise quantitativa e qualitativa de matérias veiculadas nos jornais impressos sobre as ameaças e os assassinatos. Com isso, pôde-se chegar a uma resposta sobre a questão levantada que impulsionou a elaboração deste trabalho e ter-se uma ideia de como são tratados os assuntos ligados à violência no campo. Nas considerações finais, também foi possível traçar um parâmetro sobre a cobertura ao longo dos seis anos que separam um assassinato do outro (2005-2011) e concluir qual o papel que o jornalismo impresso paraense tem cumprido nos últimos anos.

\section{BREVE HISTÓRICO DA VIOLÊNCIA NO CAMPO NO PARÁ}

Para entender melhor o surgimento dos principais fatores que levam à violência no campo - como a luta por reforma agrária, preservação do meio ambiente e melhoria das condições de vida e de trabalho a agricultores e demais trabalhadores rurais -, é importante mostrar por que e como se deu a intensificação da ocupação das terras do Estado do Pará a partir da década de 1960.

Várias áreas do Estado foram ocupadas ainda na década de 50, através de leis de incentivo e da criação de estradas, por empresários vindos do Sul e Sudeste do Brasil, que se tornaram grandes fazendeiros e obtiveram lucro com a agricultura, a exploração de riquezas minerais, entre outros benefícios, sem 
atentarem para os impactos ambientais que aquelas ocupações trariam para as matas e os rios. Mas foi na década de 60, mais precisamente no período do Golpe de 64, que a lei de incentivos foi ampliada e os trabalhadores rurais foram reprimidos pelos militares, que atendiam interesses dos proprietários de terras.

Marcionila Fernandes (1999) detalha acontecimentos importantes e decisões tomadas pelo governo em relação às terras e seus efeitos ainda na década de 1960:

Em 1965, por meio da emenda constitucional de $\mathrm{n}^{\circ} 18$, artigo 17, o governo federal estendia todas as vantagens e benefícios da política de incentivo vigente no Nordeste à região amazônica, incluindo também como beneficiário o setor agropecuário (...). Em 1966, por meio do decreto-lei $\mathrm{n}^{\circ} 5.137$, de 27 de outubro, o governo amplia os benefícios da lei dos incentivos. Tal lei foi debatida numa histórica reunião denominada 'I Reunião de Incentivos ao Desenvolvimento da Amazônia, realizada em dezembro de 1966 com a participação do então presidente da república, general Castelo Branco, governadores regionais, ministros, empresários paulistas, mais as representações de classe - a Confederação Nacional da Indústria - CNI, representada por Tomaz Pompeu de Souza Brasil Neto, e a Confederação Nacional da Agricultura - CNA, da qual era presidente Iris Meinberg. Objetivava-se com este evento mobilizar os empresários do Sul do País a participarem da 'Operação Amazônia (ou Amazônica)' com direito a opinarem sobre o projeto de lei 5.174, de 27 de outubro de 1966, que dispõe sobre a concessão de incentivos fiscais para a Amazônia. (FERNANDES, 1999, pp. 50-51)

Os empresários, além de participarem desta reunião, receberam áreas no Pará e se firmaram como empresas agropecuárias, trazendo outras pessoas para se apropriarem das terras. Esta migração causou grandes mudanças na estrutura política do Estado do Pará, pois, como os novos donos eram de outras regiões do país, tinham referências diferentes de política e economia. Sendo assim, eles foram criando seus próprios meios de gerenciar as áreas, e surgiram várias cidades, das quais estes grandes proprietários se tornaram prefeitos, onde agiam cada vez mais de acordo com seus interesses (FERNANDES, 1999, p. 55).

É importante ressaltar que, na época da concessão de terras, os empresários tinham preferência por ocupar áreas do sul do Pará, devido à concentração de riquezas naturais, inclusive minérios e solo fértil, além da proximidade aos outros Estados, facilitando o deslocamento e a exportação de produtos.

A década seguinte, de 1970, é marcada pela grande quantidade de migração de trabalhadores rurais à Amazônia, mais precisamente para o Pará, seguindo programa de incentivo à ocupação do Estado, sob o slogan "terra sem homens para homens sem terra”. Segundo Lúcio Flávio Pinto (1978), “atraídos 
por notícias sobre programas de colonização governamentais, abertura de novas estradas ou simples 'cortes de terras', os posseiros chegaram obcecados pela ideia de um lote inteiramente seu e muitas vezes são conduzidos por interesses totalmente contrários” (PINTO, 1978, p. 10).

Segundo Fernandes (1999), "o confronto é expresso na prática de violência por parte dos donos de terras contra os camponeses que buscam garantir sua identidade por meio dos assentamentos" (FERNANDES, 1999, pp.71-72). No entanto, ainda que os posseiros sejam os mais ameaçados, nem sempre os grandes fazendeiros seguem a política da pistolagem. Houve casos em que ocorreu o inverso: posseiros fizeram ameaças, destruíram cercas e mataram donos de fazendas e familiares dentro da propriedade. Alguns posseiros também foram responsáveis por invadir áreas indígenas e chegaram a acobertar erros de órgãos oficiais. E com o passar do tempo, a disputa por terra só aumentou. Em determinados casos, alguns grupos já não estavam interessados em simplesmente ocupar a terra. Como disse Lúcio Flávio Pinto (1978):

Numa época particularmente inflacionada, a busca à terra deixou de ser (...) um instrumento do desenvolvimento rural, da produção de alimentos, da utilização racional dos recursos naturais, para se transformar, na maioria dos casos, num mero negócio imobiliário, numa alta jogada financeira, num procedimento especulativo (...). A especulação não tem lógica nem coerência interna. Ela visa apenas ao lucro fácil e imediato, nem que ele custe algumas vidas e a destruição da natureza. (PINTO, 1978, p. 53)

A destruição da natureza é mais uma causa de conflitos agrários. Os agricultores defendem a preservação da natureza e também por isso são ameaçados. Seus maiores algozes, neste caso, são os madeireiros. E, com relação à questão dos conflitos, da pistolagem e das mortes nas áreas rurais, Lúcio Flávio Pinto (1978) explica por que na zona rural da Amazônia há um 'capitalismo selvagem' e acrescenta que a falta de providências traz como consequência mais problemas a serem resolvidos pelo próprio Estado:

O governo abdicou de impor às frentes pioneiras constituídas sob favores oficiais a - digamos assim - ética do Estado. O Estado tem uma visão mais coletiva e social, com maior vocação à disseminação dos benefícios. Porém, na Amazônia, o Estado abdicou de exigir o cumprimento desses princípios e deixou que a busca do lucro fácil contaminasse tudo e inclusive se sobrepusesse às exigências da Nação. Não é por outro motivo que nas selvas da Amazônia se instala um capitalismo selvagem, refratário aos custos sociais do desenvolvimento, raciocinando apenas em termos puramente comerciais, quando não especulativos de capital. É, portanto, um capitalismo predatório, que se serve do Estado e cria terríveis problemas, que ao Estado cumpre resolver, com enorme ônus. (PINTO, 1978, pp. 52-53) 
Devido a essa omissão do Estado, os conflitos agrários, especialmente no sul do Pará, eram resolvidos diretamente entre posseiros e donos de terras, "num campo de batalha onde domina o mais forte, mas não há rigorosamente vencedores" (PINTO, 1978, pp. 177-178).

Os trabalhadores rurais que chegavam às terras paraenses, portanto, já tinham ideia do que os esperava: a violência. E um dos grandes problemas que contribuíram para isso foi a não fiscalização das áreas demarcadas para cada proprietário, sendo que foi determinado que cada dono de terra podia ocupar, no máximo, 3.000 hectares, o que acabou se estendendo a milhões de hectares, sem que o poder público interferisse.

Ronaldo Barata (1995) ressalta que a desigualdade socioeconômica entre o dono da terra e o trabalhador, somada à falta de proteção por parte do poder público, resulta na escravidão e, por fim, no assassinato dos menos favorecidos.

O assassinato, como crime de encomenda, é a expressão final de toda uma prática de violência que permeia o conflito agrário: a ostensiva prática da escravidão por dívidas - a peonagem; a violenta destruição patrimonial dos bens do trabalhador rural: suas casas e suas plantações; isto tudo até chegar ao crime de tocaia em que o trabalhador, fraco e desprotegido, não tem condições de se defender, nem a proteção do Poder Público para sua vida. (BARATA, 1995, p. 10)

Com base nisso, em 1980, criou-se o Grupo Executivo das Terras do Araguaia-Tocantins (Getat) para atuar em Marabá, São Félix do Xingu, Parauapebas, Redenção e Conceição do Araguaia. Na mesma ocasião, foi criado o Grupo Executivo das Terras do Baixo Amazonas (Gebam). Ambos tinham o objetivo de controlar os conflitos e garantir a política de terras, principalmente para não prejudicar o andamento do Projeto Grande Carajás e do Projeto Jari, respectivamente.

Entre os anos de 1894 e 1985, foram criados sindicatos patronais, dirigidos por pessoas vinculadas aos fazendeiros: o Sindicato Rural de Redenção, o Sindicato Rural de Xinguara e o Sindicato Rural de Rio Maria. A União Democrática Ruralista (UDR) foi formada em Altamira, em 1987, com o objetivo de garantir força e apoio aos proprietários de terras, tendo a adesão de profissionais como médicos, comerciantes, entre outros.

Alguns órgãos e autarquias também foram fundados, entre 1970 e 1980, em prol da reforma agrária, da proteção ao meio ambiente e a federalização de questões do Estado, como os conflitos gerados pelas ocupações no campo. São eles: Instituto Nacional de Colonização e Reforma Agrária (Incra); Instituto de Terras do Pará (Iterpa); Instituto Brasileiro de Meio Ambiente e Recursos Naturais 
(Ibama); Ministério Extraordinário para o Desenvolvimento e a Reforma Agrária (Mirad); e Instituto do Homem e Meio Ambiente da Amazônia (Imazon).

Apesar da tentativa de organizar a ocupação nas áreas rurais do Estado e combater a violência, a década de 1990 não foi muito diferente. Segundo Fernandes (1999), "nos primeiros seis meses de 1991, a Polícia Federal resgatou 800 homens, em regime de trabalho escravo, de seis propriedades" (FERNANDES, 1999, pp.119-120).

Marcionila Fernandes (1999) também ilustra diferentes pontos de vista em duas informações verbais. A primeira argumenta em favor do trabalhador rural:

'O cara está ali para tirar o sustento da família. Para trabalhar, tratar dos filhos, criar a família, porque não tem outro meio. Então, é uma questão que ele está disposto a lutar pela terra, porque é uma questão de vida ou morte. Se não, vai ter que trabalhar na fazenda em troca de boia, em troca de comida (Informação Verbal, 1991e).' (FERNANDES, 1999, p. 124)

E a segunda explicita o modo de pensar de um grande proprietário de terra:

'É um dirigente da UDR que sentencia: 'Serviço tem. Quem quiser trabalhar tem serviço, eu procuro gente para trabalhar e ninguém aparece, eles só querem é desordem, eles não querem trabalhar (Informação Verbal, 1991c).' (FERNANDES, 1999, p.124)

Até hoje se pratica a violência no campo de diversas formas, pois não são poucos os registros em delegacias, as notícias publicadas pelos jornais, as denúncias a diversos órgãos estaduais e federais, etc. E, como descreve Ronaldo Barata (1995):

Não apenas se pratica a violência direta, mas também a indireta, aquela que provoca uma alteração nas condições de sobrevivência da vítima. Não apenas a violência em ato, mas também a contínua ameaça como forma de intimidação, o que torna muitas vezes a situação caracterizada por uma atmosfera enganosa de paz aparente, mas na qual o trabalhador reconhece a sua face armada que coloca em xeque a sua sobrevivência e de sua família. (BARATA, 1995, pp. 10-11)

E é evidente que esta prática continua em vigor devido à falta de medidas tomadas pela Justiça. Porém, vê-se que os moradores e trabalhadores rurais não perdem as esperanças. Os ameaçados continuam lutando por um espaço para garantir seu sustento e de sua família, unindo-se com outros trabalhadores que estão na mesma situação, denunciando e pedindo proteção ao governo, não se deixando intimidar. Estas pessoas também contam com o auxílio da Comissão Pastoral da Terra (CPT). 


\section{A COMISSÃO PASTORAL DA TERRA}

A CPT foi fundada em 1975 pela Conferência Nacional dos Bispos do Brasil (CNBB), que tem como missão realizar trabalhos no Brasil espalhando exemplos de solidariedade, esperança, fraternidade e justiça, exatamente o que a Igreja Católica propõe aos cristãos, usando como exemplo Jesus, seus ensinamentos e práticas do bem e amor ao próximo. Este trabalho é de grande valor para os mais pobres e que estão em situações de desvantagem, sem apoio das autoridades.

A CPT segue um trabalho junto às comunidades, que busca proporcionar dignidade e justiça a posseiros, índios, trabalhadores rurais e lideranças populares. Poucos anos depois de fundada, a CPT se tornou uma entidade ecumênica e recebeu apoio de ajudantes de outras igrejas cristãs. Uma delas é a Igreja Evangélica de Confissão Luterana no Brasil (IECLB).

A primeira região onde a CPT atuou foi a Amazônia, se estendendo, posteriormente, para todo o Brasil, pois se percebeu que em todo o país havia conflitos no campo e a história se repetia: trabalhadores rurais lutando por uma pequena área de terra para viver e tirar seu sustento e proprietários de grandes fazendas protegidos pelo governo e impedindo os lavradores de ocupar um espaço.

Vale ressaltar que a CP'T age de acordo com a realidade de cada região, mas sempre com foco nos direitos humanos. Em 1985, a comissão decidiu registrar e organizar dados de assassinatos, ameaças de morte, trabalho escravo, expulsões, prisões, entre outros atos violentos em áreas rurais. Estes dados são publicados anualmente no Livro de Conflitos no Campo no Brasil.

Os agentes da CPT seguem várias diretrizes: teológicas; éticas; políticas; pedagógicas; históricas e científicas. Em 2002, a CPT incluiu em seu plano de apoio casos envolvendo conflitos por água, tomando como principais eixos de ação a terra, a água e os direitos humanos. Implícito nos eixos está o desenvolvimento sustentável, o que garante às famílias sobrevivência em harmonia com o ambiente, com valores baseados na espiritualidade. Atualmente, a CPT é composta por 21 regionais. O coordenador da regional que abrange o Pará é o padre Paulo Joanil da Silva, que comentou sobre a lista de assassinatos da CPT:

Por razões óbvias, a CPT não possui uma listagem de todos os assassinatos ocorridos em todas as regiões do país - muitas vezes em lugares isolados, sem comunicação, sem entidades que possam fazer o caso vir a público. E mesmo aqueles que constam na listagem muitas vezes não trazem as informações básicas, como nome da vítima e data do crime - é assim que 
a informação chega a partir das CPTs locais. No entanto, a lista é bastante completa (...) e inclui diversas informações sobre os conflitos que levaram aos assassinatos. (VIANA, 2007, p. 19)

Ressalta-se a importância da lista de assassinatos para fins de documentação e acompanhamento dos casos, porém, mais importante é a divulgação da lista de ameaçados anualmente, pois com ela a CPT pode ajudar na questão da denúncia dos ameaçadores aos órgãos públicos e também na exigência de proteção por parte do governo aos trabalhadores. Segundo o padre Paulo da Silva, em entrevista concedida à autora deste trabalho (2013), a imprensa também pode ajudar, no sentido de pressionar o governo a tomar medidas de proteção, e o jornal é mais uma prova a favor dos ameaçados:

Não digo que resolveria [publicar ameaças de morte na imprensa], mas é muito válido. Quer dizer, se a grande imprensa notificou que José Alves de Oliveira está ameaçado de morte por fulano de tal porque quer tomar a sua terrinha, são fatos e isso vira um documento, e deixa a autoridade e a sociedade informadas previamente. (...). Quem ameaça são os poderosos, que têm grande poder aquisitivo, e sabem que vale a pena continuar ameaçando e eliminando lideranças, porque estamos acostumados com a impunidade. (SILVA, 2013)

Neste trabalho, analisam-se dois casos de vítimas da violência no campo que tiveram seus nomes registrados nos livros de conflitos agrários da CPT: o da missionária Dorothy Stang e o do casal José Cláudio Ribeiro e Maria do Espírito Santo.

\section{DOROTHY STANG}

Dorothy Mae Stang nasceu no dia 7 de junho de 1931, nos Estados Unidos, e pertencia a uma congregação da religião católica internacional chamada Irmãs de Nossa Senhora de Namur, que reúne mais de 2.000 mulheres em trabalho pastoral em todo o mundo e tem como missão principal ajudar os pobres e marginalizados.

Através desta congregação, Irmã Dorothy iniciou seu ministério no Brasil em 1966, no Maranhão, para acompanhar agricultores, que mais tarde perderam espaço para os latifundiários e acabaram migrando para Abel Figueiredo, no Pará, em 1974. "Dois anos depois, ela ajudou a fundar a CPT no Estado" (VIANA, 2007, p. 27).

Nos anos 1980, ela passou a lutar pelos direitos dos trabalhadores rurais e das famílias pobres e isoladas da região do Xingu, mais precisamente em 
Anapu. Sua ajuda consistia também em apresentar projetos de reflorestamento em áreas degradadas, além de atividades extrativistas de subsistência. Em 1997, segundo Viana (2007), a missionária e alguns militantes de movimentos sociais reivindicaram ao Incra:

Um projeto de assentamento familiar para a área rural de Anapu. O Projeto de Desenvolvimento Sustentável (PDS) foi criado com a intenção de combinar o cultivo de produtos como cacau, café e pimenta-do-reino à comercialização da produção local - açaí, cupuaçu e castanha-do-pará. (VIANA, 2007, p. 27)

Porém, Anapu era uma cidade considerada esquecida pelo poder público desde a época da ditadura, quando os moradores eram retirados por pessoas que se diziam donas daquela terra. Então, a irmã Dorothy denunciava a situação dos habitantes às autoridades do Pará e do Brasil. Argumentou, inclusive, na Comissão Parlamentar Mista de Inquérito sobre Violência no Campo, em 2004, que o fato de os grileiros não serem punidos agravava a violência sofrida pelos trabalhadores rurais. E, por não se calar diante de ameaças, ela nutriu nos fazendeiros, grileiros e madeireiros o sentimento de revolta.

Em 2003, a freira "foi declarada persona non grata pela Câmara de Anapu, "como ato de repúdio da população às ações desagregadoras por ela praticadas"” (VIANA, 2007, p. 27).

Irmã Dorothy foi assassinada com seis tiros no dia 12 de fevereiro de 2005, aos 73 anos, a 53Km de Anapu. Um dos acusados de envolvimento crime é o fazendeiro Regivaldo Pereira Galvão. Outro acusado é Vitalmiro Bastos Moura, o "Bida".

Depois que a missionária morreu, o município de Anapu recebeu mais atenção por parte do governo, como detalha Viana (2007):

Foi criada uma seção do Ministério Público Federal na cidade de Altamira, que abrange a área de Anapu, e criou-se um escritório do Incra no município. Segundo o instituto, até meados de 2006 mais de cinquenta grileiros haviam sido retirados da área do PDS, seis lotes tinham sido retomados judicialmente e todas as famílias do PDS Esperança haviam recebido crédito para a compra de insumos produtivos, além de assessoria técnica social e ambiental. (...) O governo federal criou sete novas áreas de conservação, abrangendo 6,4 milhões de hectares, no oeste do Pará, 15\% delas destinadas à proteção integral e $85 \%$ ao uso sustentável. Também criou o primeiro distrito florestal sustentável do país, com uma área de 16 milhões de hectares -5 milhões para manejo florestal. $\mathrm{O}$ decreto suspendeu a exploração de 8,2 milhões de hectares de terras públicas na margem da rodovia BR 163, para o estudo de unidades de conservação. (VIANA, 2007, pp.33-34) 
Após o assassinato, também foi criado o Comitê Dorothy, coordenado pela Irmã Margarida Pantoja e formado por pessoas de diversas religiões que se uniram para defender os direitos humanos, especialmente de trabalhadores do campo, tendo como fonte de inspiração Dorothy Stang. Uma forma de mostrar o quanto seus feitos foram importantes para o Pará e de dar continuidade ao trabalho dela.

Cerca de seis anos depois, foram assassinados José Cláudio Ribeiro e Maria do Espírito Santo, casal de ambientalistas, em Nova Ipixuna, no Pará.

\section{JOSÉ CLÁUDIO RIBEIRO E MARIA DO ESPÍRITO SANTO}

José Cláudio Ribeiro morava em Nova Ipixuna com sua companheira Maria do Espírito Santo. Ambos viviam da extração de castanhas e frutas. A reserva onde moravam é protegida por lei e o corte de árvores, ilegal. Desta forma, José Cláudio não negociava as árvores com madeireiros. Outros moradores já haviam abandonado o local devido à pressão dos empresários. Como o extrativista denunciava os crimes, seu nome e o de Maria passaram integrar a lista de ameaçados de morte divulgada pela CPT, em 2001.

José Cláudio recebia as ameaças de morte, denunciava aos órgãos competentes, mas não tinha proteção policial. Em palestras e discursos, ele afirmava que sentia medo de morrer por proteger as florestas e denunciar o comércio ilegal de madeira. Mas, mesmo assim, não deixaria de fazer o que acreditava estar certo.

Em 24 de maio de 2011, José Cláudio e Maria estavam em uma moto, retornando para sua residência, quando foram baleados e mortos por dois pistoleiros. Os acusados foram identificados e presos dias depois, mas ainda aguardam julgamento, sem data marcada. Uma testemunha, que seria a única, foi assassinada a tiros menos de uma semana depois da morte do casal.

Os julgamentos se arrastam, como no caso da Irmã Dorothy. Genivaldo Oliveira Santos, o "Gilsão", e Gilvan, além de José Rodrigues e Lindonjonson Silva Rocha, têm participação no assassinato. E a família de Maria, principalmente a irmã dela, Laissa do Espírito Santo, que passou a liderar a área que eles protegiam, recebe constantes ameaças e não tem até hoje nenhuma proteção por parte do governo.

\section{5 À GUISA DA REVISÃO DE CONCEITOS}

O estudo seminal na área do valor notícia de Galtung e Ruge(1965), apresenta um sistema de doze fatores que descrevem eventos que juntos são 
usados como uma definição de "newsworthiness". Para substanciar as premissas apresentadas os autores partem de três hipóteses básicas: a hipótese de aditividade que quanto mais fatores um evento satisfaz, maior a probabilidade de se tornar notícia; A hipótese de complementaridade de que os fatores tendem a se excluir; E a hipótese de exclusão de que eventos que satisfazem nenhum ou muito poucos fatores não se tornarão novidades. A crítica a esse modelo e sua revisão destaca que o processo aleatório do agendamento da notícia, é pontuado como um dos elementos que influenciam os processos de escolha do valor notícia. (Harcup \& O’Neill, 2016). As questões da revisão de texto também tornam o sub editor um responsável pelo processo de finalização para o leitor do valor notícia (Vanderdaele, 2017) Essa metodologia foi revisitada e adensada com elementos que demonstram também o papel econômico e político do cenário no qual são designados processos do valor notícia e de que forma os discursos somam-se à um evento e constroem o valor notícia. (Caple \& Bednarek, 2013; Caple 2014; Caple\&Bednarek; 2015)

No Estado do Pará, os jornais impressos mais lidos são O Liberal e o Diário do Pará. E, principalmente em jornais de grande circulação, embora as pautas sejam de interesse da sociedade, a política está imersa nas matérias, definindo os tipos de abordagens. A partir de então, são feitos os agendamentos e a sociedade toma conhecimento dos fatos. O interessante a ser observado é o poder que a imprensa tem sobre os leitores no sentido de fazê-los pensar sobre determinado assunto. O autor Traquina (2000) cita Cohen (1963), que afirma que:

A imprensa 'pode, na maior parte das vezes, não conseguir dizer às pessoas como pensar, mas tem uma capacidade espantosa para dizer aos seus próprios leitores sobre o que pensar. $\mathrm{O}$ mundo parece diferente a pessoas diferentes, dependendo do mapa que lhes é desenhado pelos redatores, editores e diretores do jornal que leem. (COHEN apud TRAQUINA, 2000, p. 17)

No entanto, para analisar tais afirmações, primeiramente deve-se considerar duas coisas: o fato de que os jornais fazem a abordagem da maneira que é mais interessante para eles, nem por isso deixando de ser verdadeira a notícia; e o nível de conhecimento e cultura dos leitores, tendo como base o público-alvo dos jornais. Sobre a política imersa nos impressos, o mais comum é percebermos, por meio das matérias, sua relação com o governo. Então, é feita uma seleção para decidir quais notícias serão publicadas nos jornais. Nelson Traquina (2000) explica:

Ao selecionarem e divulgarem as notícias, os editores, os profissionais da redação e os meios de difusão desempenham um papel importante na configuração da realidade política. Os leitores não só conhecem um 
determinado assunto, como também ficam sabendo qual importância atribuir a esse mesmo assunto a partir da quantidade de informação veiculada da notícia e da posição por ela ocupada. (TRAQUINA, 2000, p. 47)

As notícias são organizadas por ordem de relevância em uma prática chamada agendamento (agenda-setting), que consiste em planejar o que vai ser publicado, o que merece maior destaque, de acordo com o valor notícia, e que tipo de abordagem será feito acerca dos assuntos para se atingir o objetivo. Nelson Traquina (2000) explica a importância do agendamento citando os autores McCombs e Shaw (1993):

'O agenda-setting é consideravelmente mais do que a clássica asserção de que as notícias nos dizem sobre o que pensar. As notícias também nos dizem como pensar nisso. Tanto a selecção de objectos que despertam a atenção como a selecção de enquadramentos para pensar esses objectos são poderosos papéis no agenda-setting'. (McCOMBS e SHAW apud TRAQUINA, 2000, p. 31)

Não parece confortável a ideia de que há algo ou alguém fazendo as pessoas pensarem em determinados assuntos e que o jornalismo tem o poder de influenciar em nosso comportamento sem que percebamos. Mas Traquina (2007) traz citações de Moloth e Lester (1974-93) que explicam de maneira simples por que isso ocorre:

'Toda a gente precisa de notícias. Na vida quotidiana, as notícias contamnos aquilo a que nós não assistimos diretamente e dão como observáveis e significativos happenings que seriam remotos de outra forma'. Acrescentam: '[O] conteúdo das concepções de um indivíduo sobre a história e o futuro da sua comunidade vêm a depender dos processos pelos quais os acontecimentos públicos se transformam em tema de discurso nos assuntos públicos. (MOLOTCH e LESTER apud TRAQUINA, 2000, p. 20)

Pelo fato de o agendamento ser fundamental para uma edição de qualidade de um jornal e, no Pará, haver dois jornais de grande circulação concorrentes, é necessário que se tenha um cuidado especial na escolha da publicação de notícias. Molotch e Lester (1974-93), citados por Nelson Traquina (2000), dizem que:

A concorrência entre os promotores da notícia envolve: 1) a definição das ocorrências e/ou das questões que merecem ser constituídas em notícia, e ganham assim o direito de existir enquanto tema de discurso nos assuntos públicos e também o direito de figurar na agenda jornalística; 2) a definição das ocorrências e/ou das questões pelo seu enquadramento, isto é, pela forma como serão apresentadas e possivelmente interpretadas pela opinião pública. (MOLOTCH e LESTER apud TRAQUINA, 2000, p. 29) 
É bastante frequente os jornais O Liberal e Diário do Pará noticiarem os mesmos fatos em alguns cadernos, às vezes simultaneamente, outras vezes um dos dois dá o "furo". Algumas vezes há abordagens diferentes sobre um mesmo tema. A notícia considerada "escândalo" é a que tem grande destaque e normalmente rende matérias para outros dias, que servem de complemento. Segundo Nelson Traquina (2000):

As notícias do tipo 'escândalo' mobilizam igualmente uma narrativa já conhecida pelo público (...). O valor-notícia de consonância corresponde a esse esforço do jornalista em encaixar novas situações em velhas definições; assim, a utilização do sufixo gate, por exemplo, permite a fácil identificação de uma nova reconfiguração do mesmo corpo, do mesmo 'inventário do discurso'. (TRAQUINA, 2000, p.28)

Esta continuidade das notícias reflete o feedback dado pelos leitores, no sentido de falarem sobre os assuntos publicados nos jornais e até de questionarem e, de certo modo, exigirem mais explicações acerca dos temas, o que também é fundamental para os jornais. Este feedback serve como um termômetro para a decisão de apurar mais o assunto. Em caso positivo, é dada sequência ao tema, abordando-o de outras formas e, algumas vezes, transformando a matéria em reportagem. Em um artigo, Liliane Calado (2006) cita José Marques de Melo, dizendo que o autor:

Entende a reportagem como 'um relato ampliado de um acontecimento que já repercutiu no organismo social'. Por isso, a reportagem visa um maior detalhamento dos fatos, que muitas vezes já foram noticiados, mas mesmo assim merecem ser aprofundados e interpretados. (MELO apud CALADO, 2006)

Pode-se afirmar que o aprofundamento revela a importância do assunto para os jornais e para o público. Este, ao ver um assunto que talvez nem lhe interesse ser abordado várias vezes, acaba considerando relevante. Foi a esta conclusão que Iyengar, Peters e Kinder chegaram: "Os expectadores expostos às notícias dedicadas a um problema em particular ficam mais convencidos da sua importância. Os programas das redes noticiosas parecem possuir uma poderosa capacidade de moldar a agenda pública" (IYENGAR, PETERS e KINDER apud TRAQUINA, 2000, p. 32). Há teorias que explicam este "convencimento". Habermas (2003), por exemplo, fala sobre o conceito de opinião pública:

É considerada 'pública' a opinião de um grupo quando ela subjetivamente se impõe como a opinião dominante: o membro individual do grupo tem uma (provavelmente errônea) concepção quanto à importância da sua opinião e do seu comportamento, ou seja, de quantos dos demais membros, e quais deles, partilham ou rejeitam o hábito ou a perspectiva por ele defendida. (HABERMAS, 2003, pp. 280-281)

Novos Cadernos NAEA • v. 20 n. $1 \cdot$ p. 111-133• jan-abr 2017 
No entanto, ressalta-se que determinado grupo da sociedade, apontado por estudiosos como a "massa", simplesmente recebe informações sem buscar outras fontes. Habermas (2003) expõe a ideia de C.W. Mills, que afirma que, "numa massa, muito menos gente expressa opiniões do que as recebe, pois a comunidade do público torna-se uma coleção abstrata de indivíduos que recebem impressões dos meios de comunicação de massa" (C.W. MILLS apud HABERMAS, 2003, p. 289).

Existem também os que expressam opiniões sobre as informações que recebem e, a partir daí, levanta-se uma questão importante: qual grupo ilustraria o conceito de opinião pública? Habermas (2003) explica que:

Dois caminhos se apresentam fundamentalmente para se definir o conceito de opinião pública. Um conduz de volta a posições do liberalismo, que, em meio a uma esfera pública desintegrada, queria salvar a comunicação, bem no seio de um público meramente aclamativo, num círculo interno de representantes capazes de serem no âmbito público os formuladores de opinião, um público pensante bem no meio do público apenas aclamativo. (...) O outro caminho leva a um conceito de opinião pública que abstrai completamente de critérios materiais como racionalidade e representação, limitando-se a critérios institucionais. (HABERMAS, 2003, pp. 276-277)

Ainda sobre este assunto, Habermas (2003) cita o autor Landshut, que "registra, por um lado, o fato de que 'no lugar da opinião pública surge a disposição subjetiva, em si indeterminada. Ela é, toda vez, orientada para esta ou aquela direção através de determinadas medidas e acontecimentos" (LANDSHUT apud HABERMAS, 2003, p. 275). E a maioria das pessoas, ao absorver informações sem o intuito de fazer uma reflexão mais aprofundada, demonstra que precisa desta orientação. Sobre isso, Nelson Traquina (2000) afirma que:

A 'necessidade de uma orientação' é definida como a junção de duas variáveis: alto interesse e um alto nível de incerteza. Assim, o efeito do agendamento ocorre com pessoas que têm grande necessidade de obter informação sobre um assunto; devido a esta 'necessidade de orientação', estas pessoas expõem-se mais aos media noticiosos, provocando maiores efeitos do agendamento. (TRAQUINA, 2000, p. 33-34)

Ainda assim, os profissionais da redação dos jornais procuram fornecer o máximo de informações possível, não só para manter as pessoas cientes do que ocorre no dia a dia, mas também para levantar discussões e cobrar respostas acerca de tais acontecimentos. O agendamento destas matérias é feito cuidadosamente para que elas sejam repassadas ao público da maneira pretendida.

Seguindo a linha do tema, foram analisados o Diário do Pará e O Liberal quanto à produção das matérias e a prioridade dada ao tema nas publicações das edições diárias, baseando-se na teoria do agendamento. 
O jornal impresso O Liberal foi fundado em 1946, fruto de uma sociedade entre o então governador Magalhães Barata, do Partido Social Democrata (PSD), e correligionários de Alberto Engelhard, responsável pela administração de Belém. A missão do jornal era representar o governo e defendê-lo das críticas veiculadas pela Folha do Norte. Em 1966, passou a pertencer ao empresário Rômulo Maiorana. O Liberal hoje é presidido por Rômulo Maiorana Júnior. O principal concorrente deste jornal é o Diário do Pará.

Já o Diário do Pará foi fundado por Laércio Wilson Barbalho, em 1982, e pertence ao Grupo RBA de Comunicação. O "Diário" foi criado em meio à ditadura, para fins políticos: além de uma campanha em favor das 'Diretas, já', serviu para impulsionar a candidatura de Jader Barbalho, do Partido do Movimento Democrático Brasileiro (PMDB), ao Governo do Estado. O candidato saiu vitorioso e o jornal continuou funcionando, para promover suas ações e proteger seu governo, apontar críticas à oposição e noticiar outros fatos de interesse do público. Hoje, o diretor-presidente é Jader Barbalho Filho, neto do fundador.

\section{O CASO DOROTHY STANG: ANÁLISE DA COBERTURA DOS JORNAIS DIÁRIO DO PARÁ E O LIBERAL}

De acordo com os objetivos do trabalho, decidiu-se analisar o total de 21 edições de cada um dos jornais, ou seja, o período de três semanas: a que antecedeu o crime, a semana em que o crime ocorreu e a seguinte. Posteriormente, foram colhidas as informações, sendo possível não só fazer a análise quantitativa e qualitativa como também cruzar os dados. A primeira a ser apresentada é a quantitativa do jornal O Liberal:

Tabela 1 - Dados quantitativos do jornal O Liberal: número de materiais publicados sobre o caso Dorothy Stang

\begin{tabular}{l|c}
\hline Período & Matérias O Liberal \\
\hline De 05 a 11 de fevereiro & 0 \\
\hline De 12 a 18 de fevereiro & 172 \\
\hline De 19 a 25 de fevereiro & 132 \\
\hline Total & $\mathbf{3 0 4}$ \\
\hline
\end{tabular}

Fonte: O Liberal, edições do período de 05/02/05 a 25/02/05

Na semana anterior ao assassinato da Irmã Dorothy, nada foi publicado sobre ameaças de morte. $\mathrm{Na}$ semana do crime, devido à repercussão nacional e internacional, o jornal O Liberal divulgou 172 elementos informativos, 
quantidade grande para um jornal cujo caderno principal tem, em média, 10 páginas. Na semana posterior, o número continua elevado (132), porém nota-se uma queda em relação à semana anterior. A tabela seguinte mostra o total de materiais publicados pelo Diário do Pará sobre o caso:

Tabela 2 -Dados quantitativos do Diário do Pará: número de materiais publicados sobre o caso Dorothy Stang

\begin{tabular}{l|c}
\hline Período & Matérias Diário do Pará \\
\hline De 05 a 11 de fevereiro & 0 \\
\hline De 12 a 18 de fevereiro & 164 \\
\hline De 19 a 25 de fevereiro & 149 \\
\hline Total & $\mathbf{3 1 3}$ \\
\hline
\end{tabular}

Fonte: Diário do Pará, edições do período de 05/02/05 a 25/02/05

Nesta, percebe-se também que na primeira semana não teve registro sobre a situação da missionária, somente após o assassinato. $\mathrm{Na}$ semana em que ela morreu, foram contados 164 materiais. Essa expressividade no número de matérias acompanha a questão clássica apontada na teoria do valor notícia (Galtung \& Ruges, 1965). Na semana seguinte, o resultado também foi menor: 149, ou seja, 15 a menos.

As próximas duas tabelas mostram dados qualitativos de ambos os jornais. São os mesmos resultados anteriores, porém os elementos informativos estão discriminados.

Tabela 3 - Dados qualitativos do jornal O Liberal: tipos de materiais publicados sobre o caso Dorothy Stang

\begin{tabular}{l|c|c}
\hline Material & De $\mathbf{1 2}$ a $\mathbf{1 8}$ de fev. de 2005 & De 19 a 25 de fev, de 2005 \\
\hline Manchete de capa & 5 & 4 \\
\hline Chamada de capa & 5 & 2 \\
\hline Foto de capa & 10 & 5 \\
\hline Entrevista & 0 & 0 \\
\hline Fotolegenda & 23 & 36 \\
\hline Nota & 33 & 6 \\
\hline Coluna & 5 & 16 \\
\hline Manchete de página & 16 & 54 \\
\hline Submanchete & 73 & 0 \\
\hline Charge & 0 & 1 \\
\hline Infográfico & 2 & $\mathbf{1 3 2}$ \\
\hline Total & $\mathbf{1 7 2}$ &
\end{tabular}

Fonte: O Liberal, edições do período de 12/02/05 a 25/02/05 
Ao se observar a tabela 3, nota-se que alguns elementos estiveram em menor quantidade no período de 19 a 25 de fevereiro com relação à anterior, a manchete de página permaneceu em mesmo número e notas e colunas aumentaram.

A seguir, a tabela 4 expõe os dados qualitativos do jornal Diário do Pará: Tabela 4 - Dados qualitativos do jornal Diário do Pará: tipos de materiais publicados sobre o caso Dorothy Stang

\begin{tabular}{l|c|c}
\hline Material & De 12 a 18 de fev. de 2005 & De 19 a 25 de fev. de 2005 \\
\hline Manchete de capa & 6 & 5 \\
\hline Chamada de capa & 2 & 6 \\
\hline Foto de capa & 11 & 7 \\
\hline Entrevista & 0 & 1 \\
\hline Fotolegenda & 46 & 45 \\
\hline Nota & 25 & 10 \\
\hline Coluna & 5 & 5 \\
\hline Manchete de página & 13 & 11 \\
\hline Submanchete & 52 & 58 \\
\hline Charge & 2 & 0 \\
\hline Infográfico & 2 & $\mathbf{1 4 9}$ \\
\hline Total & $\mathbf{1 6 4}$ & \\
\hline
\end{tabular}

Fonte: Diário do Pará, edições do período de 12/02/05 a 25/02/05

$\mathrm{Na}$ tabela acima, percebe-se diferença na quantidade de materiais. $\mathrm{Na}$ semana seguinte ao crime, a maioria dos elementos sofreu queda, mas o número de chamadas de capa, de entrevista e de submanchetes subiu. O número de colunas permaneceu o mesmo.

\section{AVALIAÇÃO DA COBERTURA}

Considerando a relevância do tema violência no campo e, além disso, o assunto, aliado aos conceitos de agendamento, valor notícia e opinião pública, pode-se dizer que o caso Dorothy foi bastante valorizado pelos jornais. O caso trouxe à tona questões que estavam "esquecidas" e, com a pressão da sociedade e de autoridades internacionais, que cobravam explicações do Governo do Pará e do Brasil, os jornais buscaram o máximo de informações.

Não saiu nenhuma nota sobre o perigo que a missionária corria antes de sua morte. Mas, aproveitando a ocasião, os jornais citaram outras lideranças ameaçadas de morte, cobrando providências do governo em nome da população. 
As cobranças são válidas, o problema é ter de ocorrer uma tragédia para então prestarem atenção aos conflitos agrários e à carência de estrutura e fiscalização nos municípios, que acabam vitimando tantas pessoas. A questão agrária no Pará adquire então o caráter de valor notícia pelas pressões impostas pelo cenário do entorno como aponta a literatura mais recente (Caple \& Bednarek, 2013; Caple 2014; Caple \& Bednarek; 2015)

\section{O CASO JOSÉ CLÁUDIO RIBEIRO E MARIA DO ESPÍRITO SANTO: ANÁLISE DA COBERTURA DOS JORNAIS DIÁRIO DO PARÁ E O LIBERAL}

Para traçar o panorama, foi usada a mesma metodologia do caso da Irmã Dorothy. O período a ser pesquisado foi também uma semana antes, a semana do assassinato e a semana seguinte, totalizando 21 edições dos jornais, com início no dia 17 de maio de 2011 e a última edição, do dia 06 de junho de 2011.

Tabela 5 - Dados quantitativos do jornal O Liberal: número de materiais sobre o caso José Cláudio Ribeiro

\begin{tabular}{l|c}
\hline Período & Matérias O Liberal \\
\hline De 17 a 23 de maio & 0 \\
\hline De 24 a 30 de maio & 38 \\
\hline De 31 de maio a 6 de junho & 30 \\
\hline Total & $\mathbf{6 8}$ \\
\hline
\end{tabular}

Fonte: O Liberal, edições do período de 17/05/11 a 06/06/11

Percebe-se, na tabela 5, que na semana que antecede o crime não foi noticiada nenhuma ameaça de morte aos extrativistas no jornal $O$ Liberal. No período em que o casal foi assassinado, foram publicados 38 elementos informativos; mais do que na semana seguinte. A tabela 6 traz os dados do jornal Diário do Pará referentes ao casal:

Tabela 6 - Dados quantitativos do jornal Diário do Pará: número de materiais sobre o caso José Cláudio Ribeiro

\begin{tabular}{l|c}
\hline Período & Diário do Pará \\
\hline De 17 a 23 de maio & 0 \\
\hline De 24 a 30 de maio & 33 \\
\hline De 31 de maio a 6 de junho & 17 \\
\hline Total & $\mathbf{5 0}$ \\
\hline
\end{tabular}

Fonte: Diário do Pará, edições do período de 17/05/11 a 06/06/11 
Segundo a tabela acima, o Diário do Pará também não divulgou nada sobre José Cláudio e Maria do Espírito Santo uma semana antes do crime. Na semana seguinte, foram publicados 33 materiais tratando do assassinato e, uma semana depois, este número caiu para 17, totalizando 50 em 14 dias.

As tabelas 7 e 8 trazem dados qualitativos dos jornais O Liberal e Diário do Pará.

Tabela 7 - Dados qualitativos do jornal O Liberal: tipos de materiais sobre o caso José Cláudio Ribeiro

\begin{tabular}{l|c|c}
\hline Material & $\begin{array}{c}\text { De 24 a 30 de maio de } \\
\mathbf{2 0 1 1}\end{array}$ & $\begin{array}{c}\text { De 31 de maio a 06 de } \\
\text { junho de 2011 }\end{array}$ \\
\hline Manchete de capa & 2 & 0 \\
\hline Chamada de capa & 2 & 3 \\
\hline Foto de capa & 3 & 0 \\
\hline Entrevista & 0 & 1 \\
\hline Fotolegenda & 7 & 4 \\
\hline Nota & 3 & 4 \\
\hline Coluna & 3 & 2 \\
\hline Manchete de página & 6 & 4 \\
\hline Submanchete & 10 & 10 \\
\hline Charge & 2 & $\mathbf{3 0}$ \\
\hline Infográfico & 0 & 1 \\
\hline Total & $\mathbf{3 8}$ & \\
\hline
\end{tabular}

Fonte: O Liberal, edições do período de 24/05/11 a 06/06/11

No período de 24 a 30 de maio de 2011, semana em que ocorreu o crime, quase todos os elementos que saíram estão em maior número do que na semana seguinte, de 31 de maio a 06 de junho, exceto infográfico, chamada de capa, nota e uma entrevista, cuja quantidade aumentou, e submanchetes (mesma quantidade). Os eventos não adquirem na semana do crime uma relevância que os posicione como valor notícia seguindo a propensão de se localizar discursivamente em espaços de menor evidência (Caple \& Bednarek; 2015).

Sobre os dados qualitativos do Diário do Pará, segue a tabela indicativa: 
Tabela 8 - Dados qualitativos do Diário do Pará: tipos de materiais sobre o caso José Cláudio Ribeiro

\begin{tabular}{l|c|c}
\hline Material & $\begin{array}{c}\text { De 24 a 30 de maio de } \\
\mathbf{2 0 1 1}\end{array}$ & $\begin{array}{c}\text { De 31 de maio a 06 de } \\
\text { junho de 2011 }\end{array}$ \\
\hline Manchete de capa & 0 & 0 \\
\hline Chamada de capa & 0 & 1 \\
\hline Foto de capa & 2 & 0 \\
\hline Entrevista & 0 & 0 \\
\hline Fotolegenda & 1 & 0 \\
\hline Nota & 11 & 7 \\
\hline Coluna & 2 & 1 \\
\hline Manchete de página & 5 & 2 \\
\hline Submanchete & 9 & 4 \\
\hline Charge & 2 & 1 \\
\hline Infográfico & 1 & $\mathbf{1 7}$ \\
\hline Total & $\mathbf{3 3}$ & 1 \\
\hline
\end{tabular}

Fonte: Diário do Pará, edições do período de 24/05/11 a 06/06/11

Com relação à tabela 8, nota-se uma diferença maior entre as duas semanas de publicação de materiais referentes ao crime cometido contra o casal de ambientalistas. Concentrando-se em notas, submanchetes e manchetes de página na primeira semana, percebe-se que não houve aumento de quantidade em nenhum material, somente mantendo o mesmo número, no caso do infográfico (um em cada semana).

\section{AVALIAÇÃO DA COBERTURA}

Quanto à repercussão do caso e à importância de se discutir e aprofundar conhecimento, por meio do jornal, sobre a violência no campo, para entender o que deve ser feito para que diminua o número de crimes envolvendo trabalhadores e demais habitantes rurais, nota-se que o caso dos ambientalistas José Cláudio Ribeiro e Maria do Espírito Santo não teve a repercussão "merecida" para pressionar o governo a tomar medidas preventivas. E, se os editores e diretores de jornais impressos não deram a devida importância para o caso nem mesmo depois da tragédia, fica claro que as ameaças não teriam espaço no papel. 


\section{CONSIDERAÇÕES FINAIS}

Quando se comparam os dois casos através dos dados coletados, vê-se uma diferença espantosa entre as coberturas nos jornais. E, nos dois casos, comprovase que o agendamento coincide entre O Liberal e o Diário do Pará, ratificando a teoria exposta por Traquina. É válido lembrar que o caso dos ambientalistas também está relacionado à violência no campo, e eles lutavam pela preservação do meio ambiente e o desenvolvimento sustentável, assim como a missionária.

O assassinato da Irmã Dorothy ocorreu semanas depois da morte de 16 sindicalistas, em janeiro daquele ano, e no dia 04/02/2005, pouco mais de uma semana antes da morte dela, houve uma reunião entre Ana Júlia Carepa, então governadora do Pará, e autoridades de órgãos públicos federais para tratar sobre crimes no campo. Na ocasião, ela pediu proteção aos ambientalistas e às lideranças que denunciam irregularidades na zona rural do Estado. No jornal O Liberal, não foram citados nomes nem falas da governadora. No Diário, foi publicado depoimento de Ana Júlia a respeito de Dorothy, dizendo que ela é um exemplo de defensora dos direitos humanos no Pará. O jornalista paraense Ismael Machado, que na época era correspondente do jornal O Globo, chegou a emitir uma nota para o jornal carioca expondo as ameaças à missionária por parte de fazendeiros e madeireiros.

Já no período em que José Cláudio e Maria do Espírito Santo foram assassinados, faziam-se campanhas para o Plebiscito, que ocorreria no mesmo ano e decidiria se o Estado do Pará seria dividido em três, contando com o Tapajós e Carajás, além do Pará Remanescente. Além disso, estava em discussão a construção da Usina de Belo Monte. Mais um assunto que ocupava páginas dos jornais todos os dias.

Voltam, portanto, as perguntas citadas na introdução: “Como os jornais impressos paraenses cobrem os casos relacionados à violência no campo e qual a importância dada pelos jornais para este tema?”. Diante dos fatores notados anteriormente e do número decrescente de informações dos casos ao longo das semanas, pode-se concluir que os editores que fazem o agendamento sabem que o tema é relevante. No entanto, os casos são tratados como factuais, ou seja, como fatos que ocorrem no dia a dia, como acidentes. Ainda não dão a devida importância ao tema. Nem todos os casos são publicados, e alguns saem no caderno Polícia.

A lista de ameaçados continua extensa e, segundo o padre Paulo, ela é repassada constantemente para os jornais impressos e demais meios de difusão de notícias, mas somente quando ocorrem crimes é que o assunto vem à tona e 
são procuradas as autoridades para dar depoimentos sobre os casos. É preciso que os jornais deem a atenção merecida aos casos que envolvem trabalhadores rurais, lideranças de assentamentos e reservas, etc. para ajudar, por meio da divulgação de informações, autoridades a tomarem medidas de prevenção e outras providências em prol dos direitos humanos.

\section{REFERÊNCIAS}

BARATA, Ronaldo. Inventário da violência: crime e impunidade no campo paraense, 1980-1989. Belém: Cejup, 1995.

CALADO, Liliane de Andrade. A ciência no jornalismo impresso: Análise das reportagens do suplemento Milenium - Jornal Correio da Paraíba. Universidade Federal da Paraíba. João Pessoa, 2006.

FERNANDES, Marcionila. Donos de terras: trajetórias da União Democrática Ruralista - UDR. Belém: Naea/UFPA, 1999.

HABERMAS, Jürgen. Mudança estrutural na esfera pública: investigações quanto a uma categoria da sociedade burguesa. Rio de janeiro: Tempo Brasileiro, 2003.

PINTO, Lucio Flávio. Amazônia: no rastro do saque. São Paulo: Hucitec, 1978. TRAQUINA, Nelson. O poder do jornalismo: análise e textos da teoria do agendamento. Coimbra: Minerva, 2000.

VIANA, Natália. Plantados no chão: assassinatos políticos no Brasil hoje. São Paulo: Conrad, 2007. 
